\title{
A possible role of mouse Fused (STK36) in Hedgehog signaling and Gli transcription factor regulation
}

\author{
Alla Maloveryan - Csaba Finta • \\ Torben Østerlund • Priit Kogerman
}

Received: 16 July 2007 / Accepted: 5 October 2007 /Published online: 12 December 2007

(C) The International CCN Society 2007

\begin{abstract}
The segment polarity gene Fused $(F u)$ encodes a putative serine-threonine kinase $\mathrm{Fu}$, which has been shown to play a key role in the Hedgehog signaling pathway of Drosophila. Human FU (hFU) has been shown to enhance the activity of Gli transcription factors, targets of the signaling pathway. However, $\mathrm{Fu}^{-/-}$mice do not show aberrant embryonic development indicating that mouse $\mathrm{Fu}$ $(\mathrm{mFu})$ is dispensable for Hedgehog signaling until birth. In order to investigate if there are important differences between $\mathrm{hFU}$ and $\mathrm{mFu}$, we cloned the cDNA, analyzed expression and tested the ability of $\mathrm{mFu}$ to regulate Gli proteins. Of the tested tissues only brain and testis showed significant expression. However, in transient overexpression analyses $\mathrm{mFu}$ was able to enhance Gli induced transcription in a manner similar to $\mathrm{hFU}$. Thus, we turned to RNAi in order to test if $\mathrm{mFu}$ would be important for Hedgehog signaling after all. In one cell line with reduced $\mathrm{mFu}$ expression the Hedgehog signaling was severely hampered, indicating that $\mathrm{mFu}$ may have a role in Hedgehog signaling and Gli regulation in some cellular situations.
\end{abstract}

Keywords Fused $\cdot$ Gli $\cdot$ Hedgehog $\cdot$ Signaling .

Overexpression $\cdot$ RNA interference

\footnotetext{
A. Maloveryan · T. Østerlund $(\bowtie) \cdot$ P. Kogerman

Department of Gene Technology,

Tallinn University of Technology,

Akadeemia tee 15,

12618 Tallinn, Estonia

e-mail: torben.osterlund@ttu.ee

C. Finta

Department of Biosciences at Novum,

Karolinska Intitutet,

Hälsovägen 7, 14157 Huddinge, Sweden
}

\author{
Abbreviations \\ $\mathrm{Ci} \quad$ Cubitus interruptus \\ FACS Fluorescence assisted cell sorting \\ $\mathrm{Fu} \quad$ Fused \\ FuFL Full length Fused \\ GST Glutathione S-transferase \\ Hh Hedgehog \\ PBS Phosphate buffered saline \\ PCR polymerase chain reaction \\ RNAi RNA interference \\ RPA Ribonuclease Protection Assay \\ Shh Sonic Hedgehog \\ siRNA Small interfering RNA \\ Sufu Suppressor of Fused
}

\section{Introduction}

Hedgehogs (Hh) are secreted signaling molecules important for numerous biological processes in developing embryos of a variety of multicellular organisms from flies to humans (Hooper and Scott 2005). These proteins are also involved in several postnatal developmental processes. Furthermore, aberrant Hedgehog signaling has been linked to numerous types of cancers and several components of the pathway are either proto-oncoproteins or tumor suppressors (Hooper and Scott 2005). The Drosophila segment polarity gene Fused $(F u)$ (Preat et al. 1990) is one of the principal constituents in Hedgehog signal transduction, as activator of the transcription factor Cubitus interruptus (Ci). The Fused protein $(\mathrm{Fu})$ is likely to activate the pathway in at least two different manners. The predominant role of $\mathrm{Fu}$ is being an inhibitor of the $\mathrm{Ci}$ inhibitor Sufu. Both fruit fly and vertebrate Fused proteins contain an N-terminal kinase domain of approximately 300 residues and a much longer 
C-terminal part with regulatory properties. However, hitherto there have been no reports of phosphorylation substrates of Fused. Vertebrate Fu has also been implicated in the Hedgehog pathway since human FU (hFU) is able to enhance the gene activator function of the Gli transcription factors, orthologues of $\mathrm{Ci}$ (Murone et al. 2000; Østerlund et al. 2004; Daoud and Blanchet-Tournier 2005). Most importantly, a recent paper describes the rescue of lymphoma cells by expression of Fu or Gli1 (Dierks et al. 2007). The lymphoma cells were grown in the presence of cyclopamine (an inhibitor of the upstream pathway initiator Smo) that induces apoptosis. The apoptotic induction could be overcome by forced expression of either Fused or Gli1 (Dierks et al. 2007). However, two reports have shown that $\mathrm{Fu}^{-1-}$ mice develop normally until birth, suggesting that $\mathrm{Fu}$ is not a crucial component of the Hedgehog pathway in mice during embryonic development (Chen et al. 2005; Merchant et al. 2005). There may be several reasons for this difference. (1) Redundancy, another component is able to compensate for the loss of $F u$, (2) Fused only belongs to a branch of the pathway with limited or no influence during embryogenesis, or (3) $\mathrm{Fu}$ is not a component of the mammalian $\mathrm{Hh}$ signaling pathway. In fact it is possible that $\mathrm{mFu}$ is not able to enhance Gli induced transcription in the way $\mathrm{hFU}$ is, though they share $86 \%$ sequence identity. We have previously pointed out that there may be significant difference between Drosophila and vertebrate Hh signaling (Østerlund and Kogerman 2006). This includes differences in the way $\mathrm{Fu}$ and Sufu contribute to the signaling process. The more prominent role of Sufu in Hh signaling in vertebrates (Cooper et al. 2005; Svärd et al. 2006), as opposed to its marginal role in Drosophila, may have changed the demands for its regulation. Therefore, $\mathrm{mFu}$ may have a more peripheral role as a regulator of Gli proteins. On the other hand, soon after birth the $\mathrm{Fu}^{-/-}$ mice develop brain defects and die within 3 weeks (Chen et al. 2005; Merchant et al. 2005). This shows that $F u$ is potentially active in postnatal brain development, which may involve Hh signaling.

In order to investigate if there is a significant functional difference between mouse and human $\mathrm{Fu}$ proteins we have cloned $\mathrm{mFu}$ cDNA and analyzed its expression pattern in mouse tissues. Unlike with $h F U$, we did not detect ubiquitous expression of $\mathrm{mFu}$, although the expression was seen in the same mouse tissues that had shown high levels of expression in humans. It is thus possible that $\mathrm{mFu}$ is expressed in the same tissues as in humans, albeit at a lower level. Overexpression analyses in Hedgehog responsive cells show that $\mathrm{mFu}$ is able to enhance Gli induced transcription similar to $\mathrm{hFU}$. Thus, we did $\mathrm{mFu}$ silencing by means of RNA interference in the same cell line. We obtained two stable transformants and one of them clearly downregulated the responsiveness to Hh. This observation provide evidence that $\mathrm{mFu}$ may have an important but limited role in Hedgehog signaling.

\section{Materials and methods}

Isolation of mFused

Adult mouse brain and testis cDNA samples (kindly provided by Dr. Kaia Palm) were used for PCR amplification with primer pair $5^{\prime}$-CCCTGGATCTATAGC TCTT-3' (mFu exon 3'-specific sequence) and 5'-CAACAGTAGG ACAGTGAAGG-3' (exon 28-specific sequence) using Expand Long Template PCR System Kit (Roche Applied Science, Basel, Switzerland) according to manufacturer's instructions. The obtained PCR products (full length (FL) and short version $(\Delta 6-26))$ were purified from agarose gels using QIAquick Gel Extraction Kit (Qiagen, Valencia CA, USA) and subcloned into pCR-BluntII-TOPO vector using the Zero Blunt TOPO PCR Cloning Kit (Invitrogen, Carlsbad CA, USA).

\section{Generation of cDNA constructs}

The Fu cDNAs were subcloned into pCTAP-C (Stratagene, La Jolla CA, USA) using the EcoRI sites to generate FuFLpCTAP and $\mathrm{Fu}(\Delta 6-26)$ pCTAP. Fu(K33R)pCTAP with Lysine 33 substituted by Arginine was generated from FuFLpCTAP by PCR mutagenesis using Expand Long Template PCR System kit (Roche) and a pair of primers carrying the appropriate point mutations. The obtained PCR product was gel-purified using JETquick Gel Extraction Spin Kit (Genomed, St. Louis MO, USA). FuFLpCTAP was digested with Eco52I (Fermentas, Vilnius, Lithuania) that cuts FuFL at position 765 (corresponding to amino acid 255) and pCTAP before and after MCS. The obtained restriction fragments encoding the kinase domain $(\mathrm{KD})$ and C-terminus (CT) of FuFL were gel-purified using JETquick Gel Extraction Kit (Qiagen) and cloned into the Eco52I sites of pCTAP vector resulting in FuKDpCTAP and FuCTpCTAP constructs, respectively. All constructs were verified by DNA sequencing. A Fu-specific siRNApSUPER (FupSUPER) construct was generated according to the pSUPER RNAi System protocol (OligoEngine, Seattle WA, USA). The sequence for small interfering RNA (siRNA) was chosen to be specific for the kinase domain coding region of both isolated $\mathrm{mFu}$ isoforms. The primers 5'-GATCCCCTCCCAACATTGTGCATATGTTCAAGAG ACATATGCACAATGTTGGGATTTTTA-3' and 5'-AGCT TAAAAATCCCAACATTGTGCATATGTCTCTTGAACATA TGCACAATGTTGGGAGGG-3' (the target sequence of $\mathrm{mFu}$ is underlined, corresponding nucleotides 180-198) were 
annealed with each other and subcloned into pSUPER vector between BamHI and HindIII sites.

The FL human Gli1EGFP construct is described in (Kogerman et al. 1999). The translated region of FL mouse Gli2 was amplified by PCR using pair of oligonucleotides containing BglII (forward) and BamHI (reverse) restriction sites and subcloned to pEGFP-C1 vector (Clontech, Palo Alto CA, USA).

To obtain a ShhC24II encoding construct, the part encoding residues 25-198 of human Shh was subcloned into pGEX-6p-2 (Amersham Biosciences, Little Chalfont, UK). This was achieved by PCR amplification of the particular part using primes also introducing the restriction sites BamHI and EcoR1 used for the subcloning. The 5' primer also introduced an enterokinase cleavage site and two leucines and the 3 'primer introduced a stop codon.

\section{ShhC24II protein purification}

The ShhC24II protein is described in (Taylor et al. 2001). The enterokinase-ShhC24II was expressed as GST-fusion protein in E. coli strain XL-Blue. Bacteria were lysed by sonication and the lysate was incubated with Glutathione Sepharose 4B Fast Flow slurry (Amersham) during $30 \mathrm{~min}$ at room temperature. The enterokinase-ShhC24II protein was cleaved with enterokinase (Invitrogen) overnight at room temperature. After cleavage the enterokinase was removed by EK-away resin (Invitrogen) according to manufacture's instructions and ShhC24II was eluted with $1 \times$ PBS.

\section{Northern blot}

Northern blot analyses were performed as previously described (Østerlund et al. 2004). Two different cDNA fragments were chosen: one in the $5^{\prime}$ end (nucleotides 216768; numbering of nucleotides is from the translational start site) and another corresponding to exon 26 of the coding region. These fragments were amplified by PCR and radioactively labeled with ${ }^{32} \mathrm{P}$-ATP using the High Prime DNA labeling kit (Boehringer Mannheim, Manheim, Germany) according to the manufacturer's instructions. The hybridization was performed in ExpressHyb (Clontech) at $68^{\circ} \mathrm{C}$ for high specificity, to commercially available mouse Multiple Tissue Northern blots (Clontech), according to the recommendations by the manufacturer.

\section{Ribonuclease Protection Assay (RPA)}

Two different riboprobes were synthesized (Fig. 2b). Sequence of probe 1 corresponded to nucleotides 1-398 of $\mathrm{Fu}(\Delta 6-26)$. Probe 2 was complementary to $\mathrm{mFu}$ cDNA fragment of exon 27 and corresponded to nucleotides $3173-3622$ of FuFL or $399-848$ of $\mathrm{Fu}(\Delta 6-26)$. Fu( $\Delta 6$
26)Topo construct was cut with $\mathrm{NcoI}$ and $\mathrm{XbaI}$ (probe 1) or $\mathrm{XbaI}$ and BamHI (probe 2) and obtained cDNA fragments were subcloned into $\mathrm{pTZ57R/T}$ vector (Fermentas) that contains $\mathrm{T} 7$ promoter site in antisense orientation $50 \mathrm{nt}$ downstream of the multiple cloning site. Prior to riboprobes synthesis the constructs were linearized with NcoI (probe 1) and $\mathrm{XbaI}$ (probe 2) and purified by phenol-chloroform extraction. Linearized $\mathrm{mFu}$ templates or pTRI-Actin-Mouse $(0.5 \mu \mathrm{g})$ (Ambion, Austin TX, USA) were in vitro translated using $20 \mathrm{U}$ of T7 RNA polymerase (Fermentas) in the presence of $15 \mu \mathrm{Ci}$ of $\left(\alpha_{-}{ }^{32} \mathrm{P}\right) \mathrm{UTP}$ (Amersham Biosciences) at $37^{\circ} \mathrm{C}$ for $1 \mathrm{~h}$. After translation, the DNA templates were digested using $10 \mathrm{U}$ of RQ DNaseI (Promega, Madison WI, USA) at $37^{\circ} \mathrm{C}$ for $1 \mathrm{~h}$. The probes were phenol-chloroform purified and diluted in $100 \mu \mathrm{l}$ of Hybridization III Buffer (RPA III kit, Ambion). RNA of dissected mouse tissues or cultured cells was isolated using RNAwiz reagent (Ambion) according to the manufacturer's instructions. Total RNA from each sample $(10 \mu \mathrm{g})$ was ethanol-precipitated, diluted in $5 \mu$ of Hybridization III Buffer and mixed with $5 \mu$ of a radioactively labeled probe. The samples were denatured at $85^{\circ} \mathrm{C}$ for $10 \mathrm{~min}$ and hybridized at $50^{\circ} \mathrm{C}$ for $16-20 \mathrm{~h}$. Nonhybridized RNA and free probes were digested with RNaseA/T1 mix in $100 \mu$ l of Digestion III Buffer (Ambion) for $1 \mathrm{~h}$ at $37^{\circ} \mathrm{C}$. The reaction was stopped by adding $40 \mu \mathrm{g}$ of Proteinase K (Fermentas) in the presence of $0.4 \%(\mathrm{v} / \mathrm{v})$ SDS. The non-digested RNA was purified by phenolchloroform extraction and resolved on a denaturing 5.5\% acrylamide gel. The gel was dried for $1 \mathrm{~h}$ at $80^{\circ} \mathrm{C}$. Radioactive bands were visualized and quantified using a Bio-Rad GS250 phosphoimager.

\section{Overexpression studies}

The NIH-3T3 cell line clone Shh-LIGHT2 (Shh-L2) (Taipale et al. 2000) was used for the overexpression assay. Shh-L2 cells are stably expressing a Gli-dependent Firefly luciferase reporter and the Renilla luciferase. The latter was used for the normalization of data. The cells were propagated in D-MEM growth medium containing $4500 \mathrm{mg} / \mathrm{ml}$ glucose, supplemented with 10\% Fetal Bovine Serum and 5\% penicillin/streptomycin, $0.1 \mathrm{mg} / \mathrm{ml}$ zeocin (Invitrogen) and $0.4 \mathrm{mg} / \mathrm{ml}$ geneticin (Sigma) at $37^{\circ} \mathrm{C}$ and $5 \% \mathrm{CO}_{2}$.

The cells were seeded at the density $7 \times 10^{4}$ cells $/$ well on 24-well plates and transfected the next day using Polyethylenimine transfection agent (PEI) (InBio) in ratio PEI: DNA=1.6 $\mu \mathrm{g}$ : $0.8 \mu \mathrm{g}$ per well. DNA used for cotransfection: $0.2 \mu \mathrm{g}$ of Gli1/Gli2-EGFP and $0.6 \mu \mathrm{g}$ of different $\mathrm{mFu}$ constructs (or with respective empty vectors). PEI was mixed with DNA in $50 \mu \mathrm{l}$ of sterile D-MEM medium for each well, incubated for $10 \mathrm{~min}$ at room temperature and added to the cells containing $200 \mu \mathrm{l}$ pr. well of D-MEM. The cells were transfected for $2 \mathrm{~h}$, after that propagated for 
$24 \mathrm{~h}$ in the normal growth medium and for additional $24 \mathrm{~h}$ in the Light medium containing $0.5 \%$ FBS. Activity was measured by luciferase assay (see below).

\section{RNA interference of $\mathrm{mFu}$ expression}

RNA interference (RNAi) of the $m F u$ gene was induced in Shh-L cell line. The cells were grown as described above and cotransfected with FupSUPER and pBABE-puro constructs in ratio 19:1 using (PEI: DNA=17 $\mu \mathrm{g}$ : $5.6 \mu \mathrm{g}$ per $10 \mathrm{~cm}$ plate). The cells were split $48 \mathrm{~h}$ after transfection and $24 \mathrm{~h}$ later the normal growth medium was replaced by the selective growth medium supplemented with $2 \mu \mathrm{g} / \mathrm{ml}$ of puromycin. Puromycin-resistant colonies were picked and propagated in 24-well plates, and eight were chosen for subsequent analysis. Efficiency of RNAi was verified by RPA using probe 2 . The established cell lines showing reduced level of mFu mRNA and Shh-L2 as a control were chosen for further analysis.

The cells were plated at the density $6 \times 10^{4}$ cells per well on 24-well plates and were transfected the next day with $0.8 \mu \mathrm{g}$ per well of pShhNpCMV (Stratagene), GLI1-EGFP or empty vector pr. well using PEI as described above. Alternatively the cells were stimulated with the $12 \mathrm{nM}$ ShhC24II. After $24 \mathrm{~h}$ post-transfection or adding of the ShhC24II, the normal growth medium was replaced with the Light medium, and cells were incubated for the additional $24 \mathrm{~h}$ prior the Luciferase assay.

\section{Luciferase assay}

The cells were rinsed in $1 \times \mathrm{PBS}$ and lysed in $50 \mu \mathrm{l}$ of Passive Lysis Buffer II (Promega). Aliquots of $10 \mu \mathrm{l}$ were used for the assay. Firefly and Renilla luciferase activities were measured using Dual Renilla/Firefly Luciferase kit (Promega) on an Ascent Fluoroscan luminometer (Thermo Electron Corporation, Waltham MA, USA) according to manufacturer's instructions. All experiments were performed at least 3 times in 4-6 replicates and the results of representative experiments are shown with standard deviations.

\section{Results}

Identification of two $\mathrm{mFu}$ isoforms

A comparative analysis of the mouse genomic and $\mathrm{hFU}$ cDNA sequences revealed the $m F$ used $(m F u)$ gene on chromosome 1 region C3 (74.90-74.94 kb by Ensembl annotation (http://www.ensembl.org)) encoding a kinase known as serine/threonine kinase 36. The $m F u$ gene is predicted to consist of 28 exons (Merchant et al. 2005) (Fig. 1a). It contains two 5'UTR exons, translation initiator codon ATG in exon 3, and Stop codon TAA in exon 28. Exons 3-9 encode the kinase domain, which is highly homologous to that of $\mathrm{hFU}$ and $\mathrm{dFu}$. The remaining exons are anticipated to encode parts important for regulatory functions of $\mathrm{Fu}$ (Murone et al. 2000; Østerlund et al. 2004).

Mouse brain and testis cDNAs were chosen for RT-PCR amplification as those, together with pancreas and the kidney, were the tissues showing the highest expression of $h F U$ (Murone et al. 2000; Østerlund et al. 2004). Two PCR products (Fig. 1b and c) were obtained using a primer pair complementary to the $19 \mathrm{nt}$-long unique sequences of the 3 rd and 28th exons in the predicted $m F u$ gene. Sequence analysis revealed that PCR product 1 (FuFL) contained exons 3-28 of the predicted $m F u$ gene encoding the fulllength (FL) version of Fu (Fig. 1b). The 2nd product shorter variant $\mathrm{Fu}(\Delta 6-26)$ - contained exons 3-5 and a part of exon 6 spliced to exon 27 a few $n$ t from the $5^{\prime}$ splice site in the FL clone (Fig. 1b).

Sequence analysis predicts a 1,314 residue long FuFL protein highly homologues to the previously described $\mathrm{hFU}$ protein, showing $97 \%$ identity in the kinase domain $(\mathrm{N}$ terminal 260 residues) and $80 \%$ identity in the regulatory domain. The identity between $\mathrm{mFuFL}$ and Drosophila $\mathrm{Fu}$ $(\mathrm{dFu})$ was lower, showing 50 and $10 \%$ identity in kinase and regulatory domain, respectively. The protein encoded by the $\mathrm{Fu}(\Delta 6-26)$ cDNA clone is 133 amino acids long due to a Stop codon generated by a frame shift close to the splicing site in exon 27.

Expression of $m F u$ in brain and testis

The expression pattern of $\mathrm{mFu}$ isoforms was analyzed in different tissues using Northern blot (Fig. 2a) and Ribonuclease Protection Assay (RPA) (Fig. $2 b$ and c). The Northern analyses of adult tissues only revealed an approximately $5 \mathrm{~kb}$ transcript in testis irrespective of the probe that was used. Also a weak band at $5.5 \mathrm{~kb}$ is seen, suggesting that $m F u$ can encode different mRNA species. It was not possible to detect any band corresponding to the $\mathrm{Fu}$ ( $\Delta 6-26)$, showing that this is only produced in small amounts and/or rapidly degraded.

For RPA analyses we used RNA from several adult mouse tissues and brain at $12 \mathrm{dpc}$ and $1 \mathrm{dpp}$ as well as from fetal brain at several stages during development. Three protected fragments were detected using probe 1 (Fig. 2b), full-length (398 nt) protection specific for $\mathrm{Fu}(\Delta 6-26)$ transcripts (indicated with $*$ ) and $323 \mathrm{nt}$ (indicated with $* *$ ) plus $76 \mathrm{nt}$ (not shown) bands for mFuFL. The mFuFL was highly expressed in the testis. Significantly lower levels of $\mathrm{mFuFL}$ were detected in the brain. This expression pattern of mFuFL was also observed using an mFuFL-specific probe (3) (data not shown). $\mathrm{Fu}(\Delta 6-26)$ was found only in testis as a minor alternative transcript. 
Fig. 1 The structure of $m F u$ gene and generated cDNA clones. a The $\mathrm{mFu}$ gene found on Chromosome 1 consists of 28 exons. The translated exons are 3-28 encoding an N-terminal serine/threonine kinase domain (exons 3-9; dark gray) and a C-terminal region (exons 10-28; light gray) suggested having regulatory functions. Untranslated parts are shown in black. b Schematic representation of the FuFL and $\mathrm{Fu}(\Delta 6-26) \mathrm{cDNA}$ clones obtained by RT-PCR as shown (arrows) in (c). Compared to the FuFL cDNA the $\mathrm{Fu}(\Delta 6-$ 26) lacks a big part from exon 6 to 26 indicated by dashed lines. The different RPA hybridizing probes are also indicated in (b). Probe 1 consist of $323 \mathrm{nt}$ before and $76 \mathrm{nt}$ after alternative splicing in $\mathrm{Fu}(\Delta 6-26)$ giving a $399 \mathrm{nt}$ long protected fragment. Probe 2 was complimentary to 449 nt of exon 27 present in both $\mathrm{FuFL}$ and $\mathrm{Fu}(\Delta 6-26)$. Probe 3 covers $550 \mathrm{nt}$ from the end of exon 4 to the middle of exon 7 and is FuFL specific

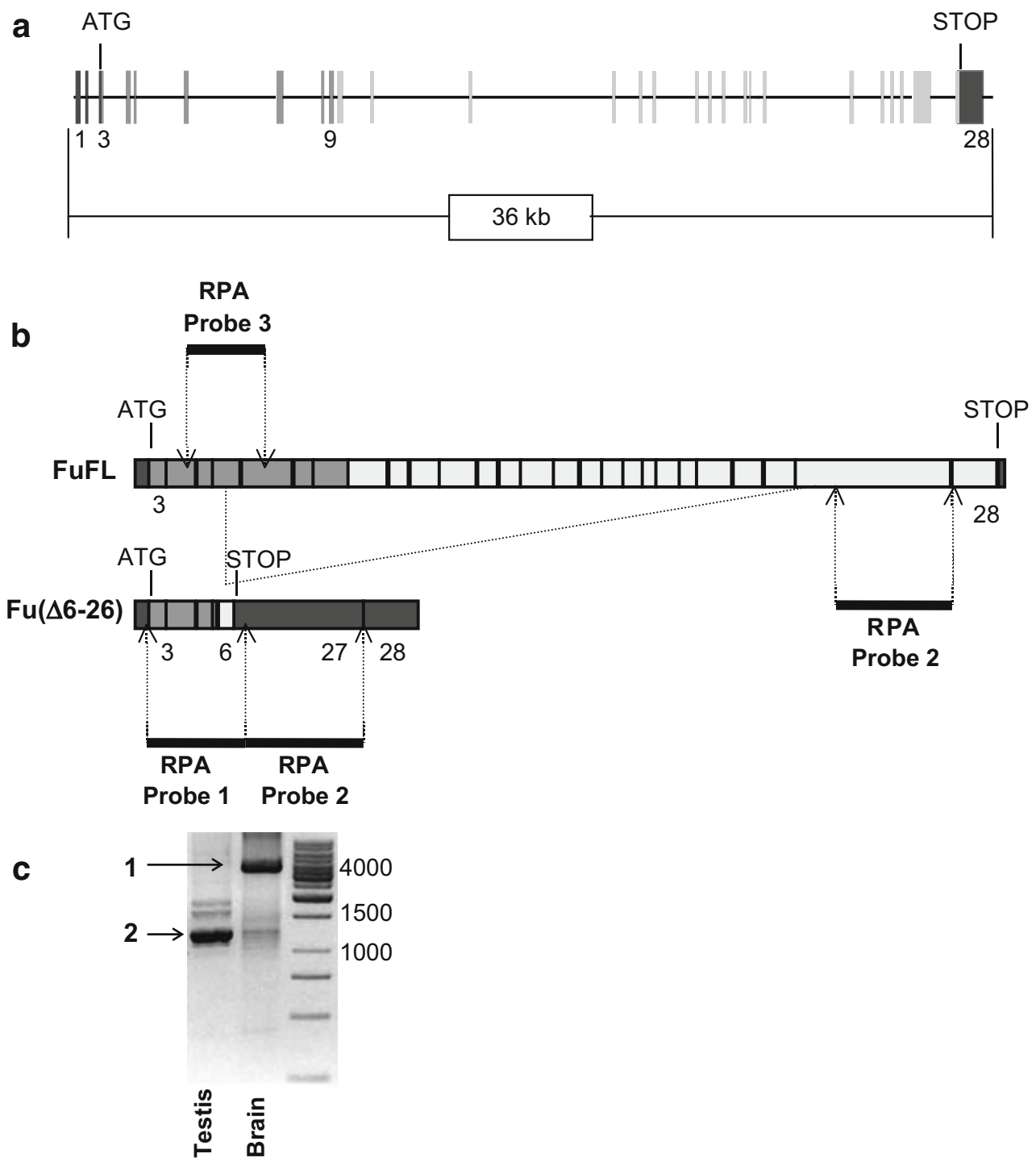

Total RNA derived from brain tissue at different stages of development (E12, E14, E16, E18, P4 and adult) was analyzed using probe 2 that recognize both $\mathrm{FuFL}$ and $\mathrm{Fu}$ ( $\Delta 6-26)$ (Fig. 2c). Expression of $\mathrm{mFu}$ was very low on E12, then gradually increased during embryo brain development but decreased after birth.

The $\mathrm{mFu}$ protein enhances Gli induced transcription

Human brain and testis are among the tissues with high $F U$ expression (Murone et al. 2000; Østerlund et al. 2004). However, $h F U$ mRNA was detected in all tested human tissues (Murone et al. 2000; Østerlund et al. 2004) suggesting a functional difference between human and mouse $F u$. We therefore tested if $\mathrm{mFu}$ is able to enhance the transcriptional activity of Gli proteins in a manner similar to hFU (Murone et al. 2000; Østerlund et al. 2004; Daoud and
Blanchet-Tournier 2005). FuFL and Fu( $\Delta 6-26)$ were overexpressed together with Gli proteins and analyzed with respect to the effect on a Gli responsive firefly luciferase reporter gene, which is incorporated in the genome of ShhLIGHT2 (Shh-L2) cells (Taipale et al. 2000). We also analyzed the effect of a full kinase domain, the regulatory domain and a kinase-inactive variant of $\mathrm{mFu}$ (the conserved lysine 33 mutated to arginine (K33R)). The data obtained were normalized with Renilla luciferase values and the results of representative experiments are shown (Fig. 3). Mouse FuFL enhances the transcriptional activity of both Gli1 and Gli2 approximately four times. The same result was achieved using mutant $\mathrm{Fu}(\mathrm{K} 33 \mathrm{R})$ indicating that the kinase activity of $\mathrm{mFu}$ is not required for the regulation of Gli-induced transcription. Co-activator potency of $\mathrm{Fu}(\Delta 6$ 26) was significantly lower, it enhanced the activity of Gli1 and Gli2 proteins 1.9 and 1.6 times, respectively. However, 
Fig. 2 The $m F u$ expression in mouse tissues. a Northern blot analysis of $\mathrm{mFu}$ expression in eight different tissues as indicated. The major $5 \mathrm{~kb}$ band is indicated with a solid arrow and the minor $5.5 \mathrm{~kb}$ band with a dotted arrow. b RPA expression analysis of $\mathrm{Fu}(\Delta 6-26)(*)$ and FuFL (**) using probe 1 in eight adult tissues and two stages of brain development. c RPA analysis of mouse brain at different developmental stages as indicated (Fused protection indicated by arrow). $\mathbf{b}$ and $\mathbf{c}$ Pure water (mQ) and yeast RNA are used as negative controls a

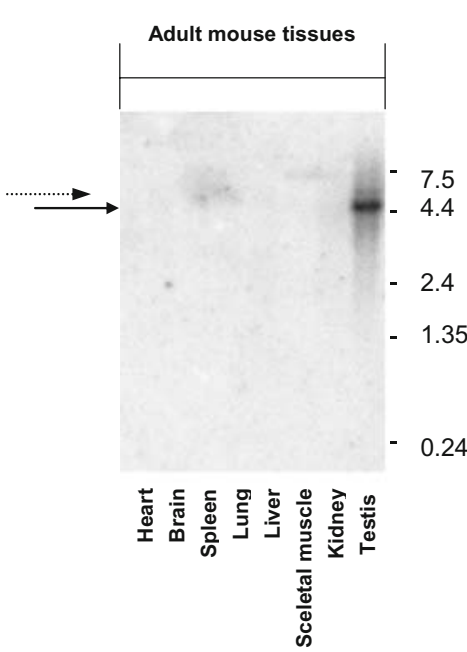

b
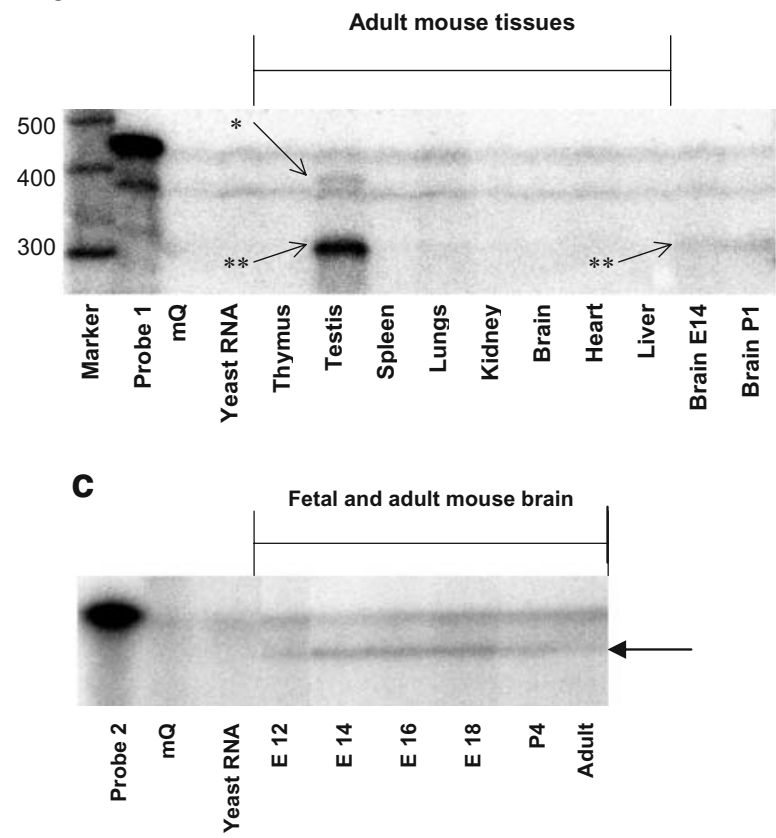

the effect of full-length kinase domain of $\mathrm{mFu}$ was only slightly weaker than $\mathrm{mFuFL}$ and, moreover, the regulatory domain of $\mathrm{mFu}$ alone could enhance the Gli activity three times, providing additional evidence that the C-terminal part of $\mathrm{mFu}$ is involved in Gli regulation. Taken together, our data demonstrate that $\mathrm{mFu}$ could enhance the activity of Gli1 and Gli2 proteins and both the kinase domain and Cterminal regulatory region of $\mathrm{mFu}$ are required for the full

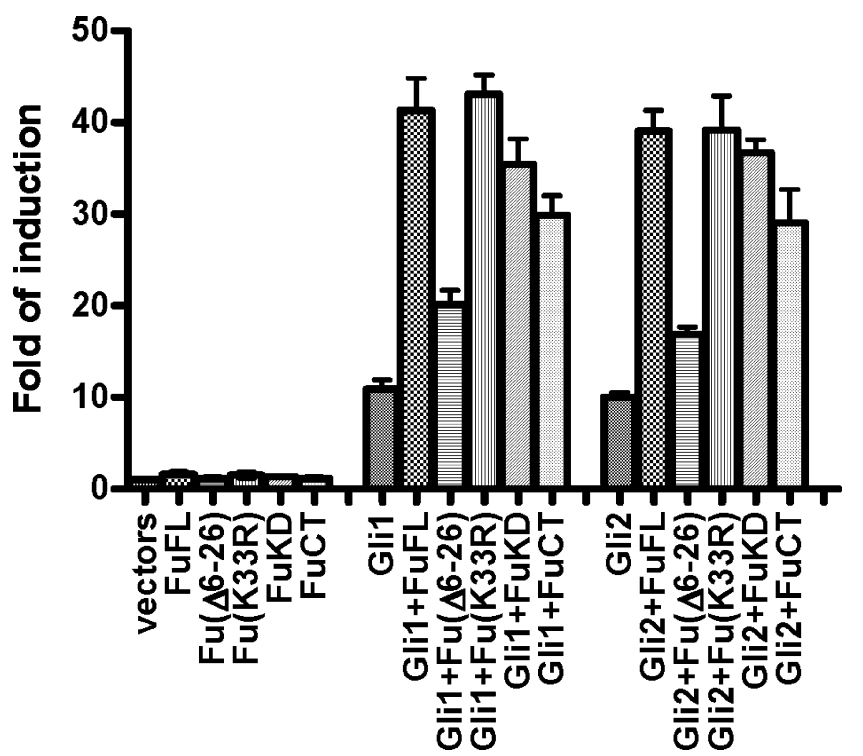

Fig. 3 Regulation of Gli1 and Gli2 by $\mathrm{mFu}$ in Shh-L cells. Different construct of $\mathrm{mFu}$ were overexpressed either alone or together with either Gli1 or Gli2 in Shh-L cells as shown. Vectors indicate transfection with empty control vectors and the results were calculated proportionally to these $(=1)$. Error-bars represent standard deviations of the calculations activation of Gli, though the potential kinase activity appears not to be crucial. These data are similar to those obtained with hFU (Murone et al. 2000; Østerlund et al. 2004; Daoud and Blanchet-Tournier 2005).

\section{Reduced $m F u$ expression impairs Shh signaling}

In the light that $\mathrm{mFu}$ and $\mathrm{hFU}$ are able to regulate Gli proteins in the same manner, we wanted to test the possibility that $\mathrm{mFu}$ is of importance for Shh signaling. To this end we used an RNA interference (RNAi) procedure to reduce Fu mRNA in Shh-L2 cells. After selection, several cell lines stably expressing $\mathrm{mFu}$ siRNA, were isolated and verified for RNAi efficiency using RPA (Fig. 4a). Compared with the control Shh-L cells two cell lines, Cell line I and Cell line II, showed significant reduction of $\mathrm{mFu}$ mRNA level. Cell line I expressed 35\% and Cell line II only $16 \%$ of the Fu mRNA control level (Fig. 4a). An actin-specific probe was used as control of expression levels (Fig. 4b). In order to assess the $\mathrm{mFu}$ protein levels in the RNAi cell lines, we employed a novel $\mathrm{mFu}$ affinity purified anti-peptide antibody produced in rabbits (InBio, Tallinn, Estonia). This antibody was not highly specific in Western blots, but could be used for comparison of expression levels of $\mathrm{mFu}$ in FACS analysis. Using this method and the $\mathrm{mFu}$ antibody, it could be determined that Cell line I expresses $\mathrm{mFu}$ almost to the same extent (62\%) as control Shh-L2 cells, whereas Cell line II expresses very low amounts (roughly as low as background (2\%); Fig. 5).

In order to test the ability of the established cell lines to transduce the Shh signal we either transfected them with the 
a

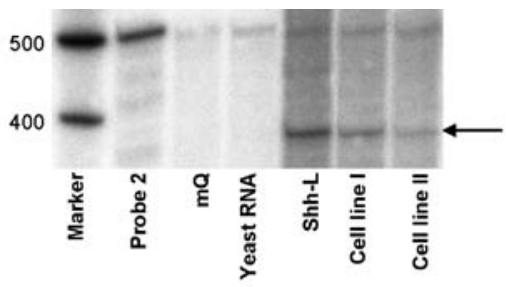

b

C

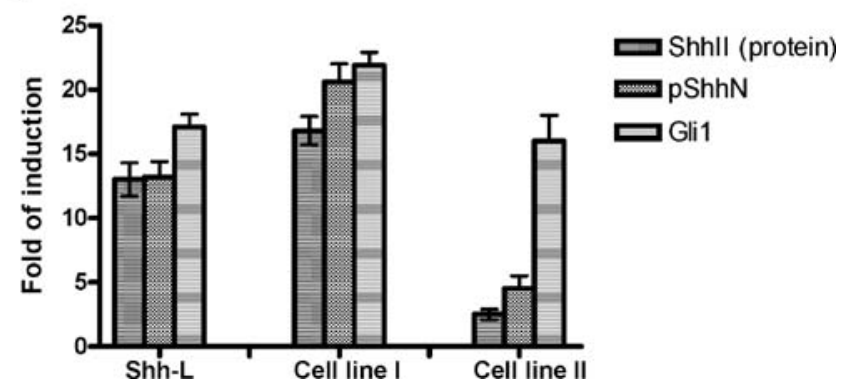

Fig. 4 Analyses of Shh-L clonal cells with reduced mFu mRNA. a RPA analysis of using probe 2 of control Shh-L cells and two cell lines (I and II) with significantly lowered $\mathrm{mFu}$ expression (Fused protection indicated by arrow). b Control RPA analysis with actin-specific probe. As negative controls were used Yeast RNA and water (mQ). The intensity of the $\mathrm{mFu}$ bands was calculated in relation to that actin bands, showing 35\% mFu expression in Cell line I and 16\% expression in Cell line II. c Control Shh-L, Cell line I and II were stimulated by Shh protein (ShhC24II), by transfection with a Shh construct or by a Gli1 construct. The stimulation of the luciferase reporter is calculated as fold induction compared to non-stimulated control cells $(=1)$. Error-bars represent standard deviations of the calculations

Shh N-terminal encoding (ShhN)-construct or stimulated directly with a highly active Shh protein variant (ShhC24II). Alternatively, luciferase expression was induced directly by transfection of a Glil construct. Activation of luciferase in the Clone I cells was achieved in all three cases like for control Shh-L2 cells (Fig. 4c). Cell line II, with lower levels of $\mathrm{Fu}$ mRNA expression, was successfully activated by Gli1 whereas Shh protein or the ShhN-construct only had minor effects (Fig. 4c), showing a severely hampered signaling pathway in these cells.

\section{Discussion}

In order to investigate the functionality of $\mathrm{mFu}$ we have cloned the cDNA and identified the exons in the genomic sequences at Ensembl (http://www.ensembl.org). This corresponds well with the human gene (Østerlund et al. 2004) and the previously published sequences (Chen et al. 2005; Merchant et al. 2005). We did not find the alternatively spliced variants identified by others (Chen et al. 2005). Instead, we identified a short variant lacking a small part of exon 6, exons 7-26 and a small part of exon 27. None of the suggested alternatively spliced variants (this work and (Chen et al. 2005)) corresponds to the variants identified in humans (Østerlund et al. 2004). Such lack of conservation in the pattern of alternative splicing between species, suggests that alternatively spliced variants of vertebrate $\mathrm{Fu}$ may not play any profound biological roles. In fact, the short variant identified by us had very little effect on Gli-induced transcription in our cellular overexpression assay.

The analyses of expression in adult tissues only show significant amounts of $m F u$ mRNA in the brain and testis. This is partly in line with the expression analyses in human tissues where the highest amounts were found in the brain, testis, pancreas and kidney (Østerlund et al. 2004). However, small amounts of $h F U$ mRNA were seen in all analyzed tissues (Østerlund et al. 2004), which we did not see in the mouse. In the embryo, $m F u$ was expressed broadly and the highest expression was detected in the brain, limbs, the neural tube and somites (Chen et al. 2005). The high expression of human and mouse $F u$ in the testis indicates a prominent role of $\mathrm{Fu}$ in this tissue. However, to assess this issue it is probably necessary to create and analyze conditional $F u$ knock-out mice or perhaps examine the testicular functions of $\mathrm{Fu}^{+/-}$mice.

In order to evaluate the potential role of $\mathrm{mFu}$ in the regulation of Gli proteins, we made overexpression analyses in the NIH3T3 cell clone Shh-L2. Expression of mFuFL enhanced the activity of Gli1 and Gli2 4-fold. This corresponds well with the results obtained with hFU. Human FU enhances the transcriptional activity of Gli2 in $\mathrm{C} 3 \mathrm{H} /$ 10T and HEK293 cells (Murone et al. 2000; Østerlund et al.
Fig. 5 FACS analyses of $\mathrm{mFu}$ RNAi cells. Cell counts of the two Shh-L2 derived RNAi cell lines (I and II), of normal ShhL2 cells (positive control) and of medium without cells (negative control; control) using an $\mathrm{mFu}$ peptide antibody. The percentage of Shh-L2 count is given below
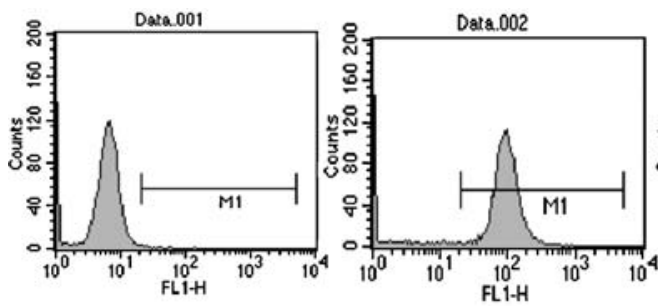

Control

$0 \%$
Shh-L2 cells $100 \%$

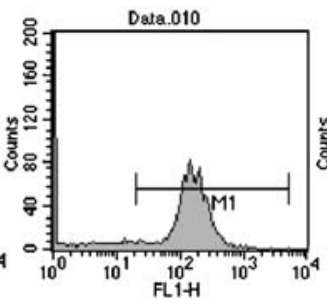

Cell line I $62 \%$

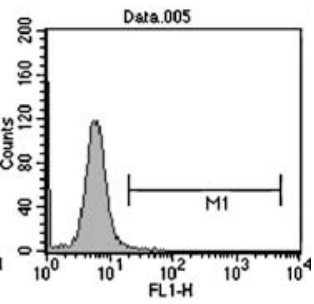

Cell line II $2 \%$ 
2004) and of GLI1 in NIH3T3C2 and SW480 cells (Daoud and Blanchet-Tournier 2005) to a similar extent. The kinase-inactive version of $\mathrm{mFu}-\mathrm{mFu}(\mathrm{K} 33 \mathrm{R})$ - exhibited the same effect on Gli activity as the mFuFL which is in line with results previously demonstrated for the kinaseinactive variant of hFU (Murone et al. 2000) and a hFU variant lacking parts of the kinase domain (Østerlund et al. 2004). Taken together, our results are in line with those previously reported for hFU and both Gli1 and Gli2 are regulated by $\mathrm{mFu}$ variants in a similar way.

The fact that both human and mouse Fu are able to enhance Gli transcriptional activity suggests that they may influence Hh signaling. To shed more light on this issue we performed RNAi analyses in the same Hedgehog responsive cells as we did the overexpression analyses. Two selected clones showed significantly lower amounts of mFu mRNA (35 and 16\% of the normal mFu mRNA level, respectively) and the cells with the lowest expression showed significantly reduced response to Shh. The fact that the two cell lines show very different results and that the previous results with $\mathrm{mFu}$ RNAi (Merchant et al. 2005) were similar to those of Cell line I, led us to speculate that the $\mathrm{mFu}$ protein levels may not be affected significantly until a very low level of mRNA is reached. Since there were no $\mathrm{mFu}$ antibodies available, which could be used for detection of the protein level, this was not done in the previous study (Merchant et al. 2005). Our FACS analyses show that only Cell line II has low $\mathrm{mFu}$ levels and this can explain why only these cells respond poorly to Shh. It is possible that Cell line I resembles the previously described Fused RNAi cells (Merchant et al. 2005), although the difference between those cells and our Cell line II may also reflect differences between the cell lines dependence on Fused protein for Hedgehog signaling. In our experiments overexpression of Glil served as a positive control and lead to reporter activation like in the control cells. These results also suggest that the level of $\mathrm{mFu}$ protein does not follow the RNAi efficiency very well. We conclude that the actual protein levels must be determined in such analyses to verify that the protein levels are in fact affected by the reduction in mRNA.

Mouse embryonic development is not dependent on $\mathrm{mFu}$, showing that neither is prenatal Hh signaling (Chen et al. 2005; Merchant et al. 2005). However, in the light that several reports, including this one, have shown that $\mathrm{Fu}$ is able to enhance Gli-induced gene activation and that reducing the $\mathrm{mFu}$ levels inhibits Shh signaling in the Shh responsive cells Shh-L2, it is possible that Fu participates in the Hh pathway by regulating Gli proteins in certain cellular contexts. For example inhibition of an upstream pathway component, Smo, by cyclopamine, was overcome by overexpression of either Fu or Gli1 in lymphoma cells (Dierks et al. 2007). An intriguing explanation would be that mammals might exert both Fu-dependent and Fu- independent $\mathrm{Hh}$ signaling, where the latter appears to dominate in the developing embryo. Other genes may compensate for the loss of $m F u$ (redundancy) or Fu may be a component in a branch of the pathway that is of little importance during embryogenesis. In the light that $\mathrm{mFu}$ is vital for postnatal brain development (Chen et al. 2005; Merchant et al. 2005), Fu may have a significant role in the Hh pathway after birth. These results suggest a restricted but identifiable role of $\mathrm{Fu}$ as a regulator of Gli proteins. Further investigations are required to assess these possibilities and our mFu RNAi Cell line II could be a helpful tool in this respect. As previously pointed out (Østerlund and Kogerman 2006), it is possible that $\mathrm{Hh}$ signaling is significantly different between Drosophila and vertebrates. This may also apply to the way Fu regulates Gli proteins. In order to fully understand Gli regulation and the $\mathrm{Hh}$ pathway, issues like possible redundancy of Fused-related proteins, as well as Fu-dependent and Fu-independent $\mathrm{Hh}$ signaling must be addressed.

Acknowledgements We are very grateful to Dr. Tõnis Timmusk and his lab for providing us with Expand Long Template PCR System Kit, mouse brain and testis cDNAs and embryonic brain RNA samples. We thank Dr. Mart Speek for the help in performing RPA, Matis Metsis for helping with retrieving our FACS data and Illar Pata for critically reading the manuscript. This study was supported by the Wellcome Trust and Estonian Science Foundation (grants 5552, 5933 to P.K. and 7279 to T.Ø.).

\section{References}

Chen MH, Gao N, Kawakami T, Chuang PT (2005) Mice deficient in the fused homolog do not exhibit phenotypes indicative of perturbed hedgehog signaling during embryonic development. Mol Cell Biol 25(16):7042-7053

Cooper AF, Yu KP, Brueckner M, Brailey LL, Johnson L, McGrath JM, Bale AE (2005) Cardiac and CNS defects in a mouse with targeted disruption of suppressor of fused. Development 132(19):4407-4417

Daoud F, Blanchet-Tournier MF (2005) Expression of the human FUSED protein in Drosophila. Dev Genes Evol 215(5):230-237

Dierks C, Grbic J, Zirlik K, Beigi R, Englund NP, Guo GR, Veelken $\mathrm{H}$, Engelhardt M, Mertelsmann R, Kelleher JF, Schultz P, Warmuth M (2007) Essential role of stromally induced hedgehog signaling in B-cell malignancies. Nat Med 13(8):944-951

Hooper JE, Scott MP (2005) Communicating with Hedgehogs. Nat Rev Mol Cell Biol 6(4):306-3317

Kogerman P, Grimm T, Kogerman L, Krause D, Unden AB, Sandstedt B, Toftgård R, Zaphiropoulos PG (1999) Mammalian suppressorof-fused modulates nuclear-cytoplasmic shuttling of Gli-1. Nat Cell Biol 1(5):312-319

Merchant M, Evangelista M, Luoh SM, Frantz GD, Chalasani S, Carano RA, van Hoy M, Ramirez J, Ogasawara AK, McFarland LM, Filvaroff EH, French DM, de Sauvage FJ (2005) Loss of the serine/threonine kinase fused results in postnatal growth defects and lethality due to progressive hydrocephalus. Mol Cell Biol 25 (16):7054-7068

Murone M, Luoh SM, Stone D, Li W, Gurney A, Armanini M, Grey C, Rosenthal A, de Sauvage FJ (2000) Gli regulation by the opposing 
activities of fused and suppressor of fused. Nat Cell Biol 2(5):310-312

Østerlund T, Everman DB, Betz RC, Mosca M, Nöthen MM, Schwartz CE, Zaphiropoulos PG, Toftgård R (2004) The FU gene and its possible protein isoforms. BMC Genomics 5:49

Østerlund T, Kogerman P (2006) Hedgehog signalling: how to get from Smo to $\mathrm{Ci}$ and Gli. Trends Cell Biol 16(4):176-180

Preat T, Therond P, Lamour-Isnard C, Limbourg-Bouchon B, Tricoire H, Erk I, Mariol MC, Busson D (1990) A putative serine/ threonine protein kinase encoded by the segment-polarity fused gene of Drosophila. Nature 347(6288):87-89

Svärd J, Heby-Henricson K, Persson-Lek M, Rozell B, Lauth M, Bergström Å, Ericson J, Toftgård R, Teglund S (2006) Genetic elimination of Suppressor of Fused reveals an essential repressor function in the mammalian Hedgehog signaling pathway. Dev Cell 10(2):187-197

Taipale J, Chen JK, Cooper MK, Wang B, Mann RK, Milenkovic L, Scott MP, Beachy PA (2000) Effects of oncogenic mutations in Smoothened and Patched can be reversed by cyclopamine. Nature 406(6799):1005-1009

Taylor FR, Wen D, Garber EA, Carmillo AN, Baker DP, Arduini RM, Williams KP, Weinreb PH, Rayhorn P, Hronowski X, Whitty A, Day ES, Boriack-Sjödin A, Shapiro RI, Galdes A, Pepinsky RB (2001) Enhanced potency of human sonic Hedgehog by hydrophobic modification. Biochemistry 40(14): 4359-4371 